\title{
Julieta Kirkwood, Ser política en Chile. Las feministas y los partidos, LOM Ediciones y Facultad de Ciencias Sociales, Universidad de Chile, 2010.
}

Lorena Armijo Garrido*

Con la reedición del libro Ser política en Chile. Las feministas y los partidos de la socióloga chilena Julieta Kirkwood, a cargo del Departamento de Sociología de la Universidad de Chile, se difunde y actualiza una de las líneas de pensamiento feminista más analítica de Latinoamérica y, probablemente, la más reconocida de Chile. Esta obra deja entrever-según la propia feminista- una historia (de mujeres) posible y real que ha permanecido oculta bajo la preeminencia de las estructuras de dominación masculina y, sin embargo, puede proyectarse como punta de lanza para la destrucción de esa dominación. Este texto fundador del feminismo chileno se constituye en un intento por recuperar de la memoria histórica, las experiencias y procesos de opresión y contestación de grupos de mujeres en Chile con el fin de que las jóvenes generaciones reconozcan esa situación y actúen en nombre de una reafirmación de su identidad.

Con una mirada marxiana, pero al mismo tiempo crítica de la primacía de la clase como único o primer objetivo de la lucha social, Kirkwood inicia su obra planteando uno de los problemas metateóricos siempre vigente en el debate científico, el referido a las posibilidades reales de este conocimiento y sus postulados universales de explicar la singularidad de la experiencia humana. Para responder a esta interrogante, la autora reconstruye la experiencia del hacer política de las chilenas explorando esa historia desconocida por un lado, y dando respuestas a la pregunta científica por otro. La obra, dividida en seis capítulos, describe ese hacer femenino organizado con pausas analíticas aclaratorias de los fenómenos socio-políticos involucrados en esas experiencias, al mismo tiempo que plantea nuevas interrogantes, obteniendo un resultado encomiable: un diálogo reflexivo entre teoría y práctica no exento de tensiones, que sólo refleja la maestría de la autora.

En el capítulo I "La formación de la conciencia feminista", Kirkwood avanza en la contradicción entre pensamiento científico y vida social, desentrañando las posibilidades reales de emancipación de las chilenas, en la concientización de su opresión, el carácter de su surgimiento como grupo con demandas propias, y las tendencias que

Socióloga y Magíster en Gobierno y Gerencia Pública, Universidad de Chile. Estudiante de Doctorado, Universidad Complutense de Madrid. 
estas peticiones le imprimen a los procesos de cambio. El objetivo de este ejercicio es claro: contribuir a la formación de una democracia real que incluya a las mujeres de todos los sectores en una redimensión de los tiempos y espacios sociales y políticos.

En el capítulo II "La mujer en el hacer político chileno", la autora describe la condición de la mujer en su relación con el mundo de la política y las percepciones sobre expresiones y demandas femeninas surgidas bajo el alero del movimiento feminista. La conclusión es lapidaria: las fuerzas políticas (izquierdistas) progresistas, al igual que las (derechistas) conservadoras, proclaman la reivindicación de valores del orden, dejando intactas las jerarquías y ordenamientos al interior de la familia. Incluso quienes pertenecen a las filas del progresismo llegan a denominarla como el "núcleo revolucionario básico", pero no actúan en nombre de su transformación. Es aquí donde emerge una crítica sustantiva al proyecto de la Unidad Popular en Chile: la no consideración y la evasión de las dimensiones que afectan a las mujeres habría precipitado en esa época como en otras, un fenómeno similar en movilización a la acción feminista, pero de cariz distinto como lo fue el proveniente de la derecha -la opresión femenina deviene en reacción, afirma Kirkwood-, frente al proyecto popular que dice ser emancipador. De ahí que el feminismo, como acción política, venga a enriquecer el carácter restrictivo que hasta ese momento tenía el concepto de liberación social y política, ya que, al incorporar a las mujeres como producto de innumerables estructuras políticas, productivas y reproductivas, revierte el análisis de lo femenino y la plantea como una problemática englobadora de la totalidad de la vida cotidiana. No se trataría, según la socióloga chilena, de incorporar a las mujeres al mundo público tal cual está, sino de demolerlo, transformando cualquier estructura de opresión y dominación.

Como una sujeta plena de historicidad, la autora en el capítulo III "Encuentro con la historia" profundiza en los contenidos, quiebres y silencios de las mujeres organizadas y movilizadas políticamente sucedidos en repetidas circunstancias en el siglo veinte, con la finalidad de explicar el momento reaccionario que se vive en dictadura. Creando una periodización sencilla, pero pertinente a los fines de la obra, define la relación política-mujer a partir del eje presencia/ausencia de hacer política determinando los orígenes, ascenso, caída, silencio, participación y cambio de protagonistas, este último marcado por el surgimiento del autoritarismo de 1973. En este capítulo se destacan los aprontes, esfuerzos y bemoles del quehacer feminista en un ambiente político y social no acostumbrado a la presencia de las mujeres en lo público.

No obstante, la socióloga sostiene que un trabajo conjunto puede producir acciones favorables a la posición de la mujer, quedando en evidencia en un hito cúlmine de la acción feminista: la obtención del voto. Bajo el título del capítulo IV "Triunfo, crisis y caída" la autora sintetiza el período de reconocimiento del derecho al voto de las mujeres, enmarcado por un largo proceso de luchas individuales, grupales y a nivel nacional en el que han confluido diversas corrientes ideológicas para la obtención de la ciudadanía política. 
Luego del éxito ciudadano, la disgregación de las fuerzas políticas y la prevalencia de objetivos distintos desencadenan el mutismo femenino. El capítulo V "Tiempos difíciles" examina las circunstancias que propiciaron la inactividad y los silencios surgidos una vez conquistados algunos derechos, al tiempo que se consideraban las restantes reivindicaciones como inconvenientes o inconsistentes, paradójicamente, en contextos de auge y profundización democrática. Su explicación a este fenómeno es clara: las mayorías femeninas son convocadas esporádicamente e invocadas desde su rol de género (privado-doméstico) por grupos políticos para la incorporación en sus respectivos proyectos, sin que eso involucre una disolución de las redes jerárquicas y disciplinarias de la familia. No es un hacer política desde las mujeres, pues no se afirmaría una exacción de su identidad, no habría una recuperación de su identidad, una negación de su condición secundaria y dependiente, por el contrario, sería una negación de los mecanismos dispuestos a su liberación.

Finalmente, el capítulo VI "Tiempo de mujeres" presenta, a modo de síntesis, la compleja relación entre teoría y praxis mediante la vinculación de lo político, el feminismo y lo popular. Kirkwood confía en la plena realización del proyecto feminista, aun cuando las circunstancias políticas de Chile de ese momento (1985) digan lo contrario, sin embargo, es cauta al afirmar la inexistencia de un acuerdo en el recorrido que seguirá de esta emancipación. Desde una interpretación feminista, plantea la necesidad de una reflexión sobre la democracia -en ese momento secuestrada-, desde una revalorización y rescate de sus contenidos. Retomando el debate inicial, sostiene que hay una distancia entre los valores postulados y las experiencias concretas: las mujeres viven en el autoritarismo en las dos esferas de acción en relación a lo político, incluso en lo privado donde se proclama su individualidad. El hacer de las mujeres como grupo o categoría cultural se instala en la marginalidad política. Este fenómeno genera dos nudos o problemas recurrentes, difíciles de abordar y solucionar para el feminismo, un nudo del saber seguido de un nudo del poder, nos dirá Kirkwood. Concluye su obra señalando la imperiosa necesidad de elaborar/recuperar el saber para sí. De la ausencia del poder y de sus prácticas, las mujeres pueden tomarse la acción -en tanto idea y acto- mediante el ejercicio del poder, nacida desde una deslegitimación de aquello que nos está privando, una liberación de sus limitaciones culturales y una práctica de la ruptura de la individualidad normativa.

De este texto se deduce, en primer lugar, las grandes dificultades que han tenido los grupos organizados de mujeres para mantener su acción política en el escenario público, así como el hecho de enfrentar día a día la obligatoriedad de las labores domésticas que suponen la reproducción de la vida física y social. En segundo lugar, desde una mirada sartreana, la autora apela a la constitución de ser sujeta mediante la conformación de proyectos vitales que reúnan búsquedas personales y colectivas en nombre de la igualdad de género. Si algo pudiera agregarse a la obra sería una reflexión acerca de las limitaciones que el proyecto feminista -en tanto constructor de nuevos marcos normativos reproductores de lógicas binarias de identidades, roles y prácticas para hombres y mujeres- supone para el hacer política de las mujeres 
que no encajan en el modelo oficial feminista, y en términos más generales, su articulación con demandas de otros grupos discriminados o excluidos que ya emergían con fuerza en la década de los ochenta. Es decir, una interpretación más amplia del hacer feminista como engranaje de múltiples relaciones sociales, donde la dicotomía opresor/subordinado cobra matices distintos según sea la posición socioeconómica, composición étnica, opción sexual y pertenencia geográfica que tengan los individuos o colectivos. En otras palabras, el feminismo integrado en una red de necesidades y demandas con las que interactúa, lucha y negocia cotidianamente. 